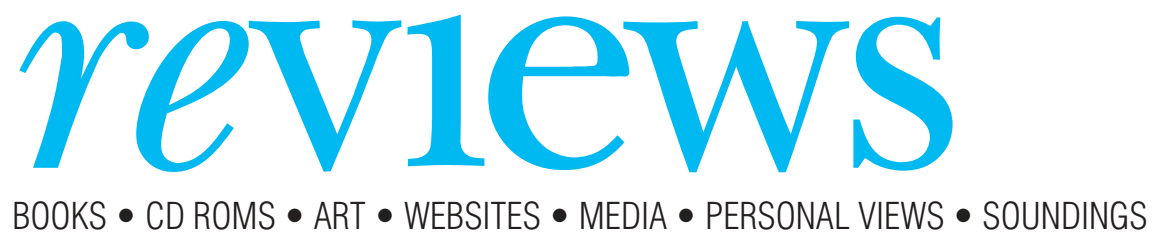

\section{Aspirin: The Story of a Wonder Drug}

Diarmuid Jeffreys

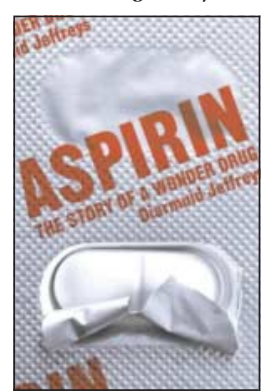

Bloomsbury, £16.99, pp 352 ISBN 0747570779

www.bloomsbury.com

Rating: $\star \star \star \star$

$\mathrm{I}$

t might seem strange to have a popular book of more than 300 pages dedicated to just one drug. But aspirin is a special case. One of the most brilliant medical historians and journalists of our time, the late Roy Porter, wrote a book called The Greatest Benefit to Mankind: A Medical History of Humanity from Antiquity to the Present (BMJ 1998;316:713). Replace "humanity" for "aspirin" in the title, and it would ideally fit the book under review. Diarmuid Jeffreys, a journalist and television producer, has written an inspiring story based on archival sources, interviews, and an amazing knowledge of the relevant literature. His book clearly demonstrates that the border between academic medical history and journalistic investigation is blurred.

Jeffreys describes aspirin as, among other things, "the most remarkable drug the world has ever seen," "one of the astonishing inventions in history," and "one of the most endurably successful commercial products of all time." Such claims are well substantiated. Aspirin is not only the subject of about

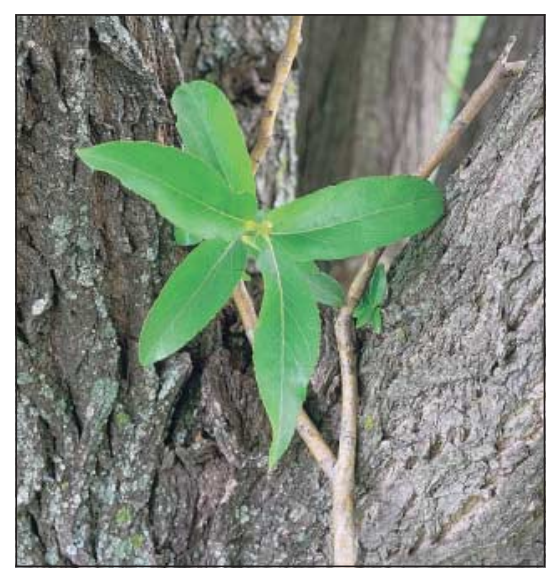

Where there's a willow...
26000 scientific papers, but also a cultural icon that has appeared in the writings of George Orwell (The Road to Wigan Pier), Graham Greene (Stamboul Train), and Edgar Wallace (The Door with Seven Locks). In 1930 the Spanish writer Jose Ortega y Gasset dubbed his era "the aspirin age."

The aspirin age is not yet over. Mashkovsky's manual, a standard reference book on pharmaceuticals for medical practitioners in the former Soviet Union, lists about 50 synonyms of aspirin with the following footnote: "The multitude of synonyms indicates the prevalence of this drug." Acetylsalycilic acid and drugs that contain it are produced by dozens of manufacturers from different countries.

Aspirin is divided into three parts. Jeffreys follows the story from ancient Egypt, where willow was used as a medicine, through to 18th century England, when the Reverend Edward Stone attempted to use willow bark for the treatment of malaria. In 1853 the French chemist Charles Gerhardt synthesised acetylsalicylic acid-the active ingredient of willow bark. In 1897 Arthur Eichengrun, a chemist employed by the Bayer company in Germany, gave his younger colleague Felix Hoffman the task of finding a version of salicylic acid that did not have the unpleasant side effects of nausea and gastric pain. Hoffman repeated Gerhardt's experiments, but Heinrich Dreser, head of the pharmacology department at Bayer, rejected the new substance.

It was Eichengrun who first tried the drug on himself and then arranged secret clinical trials in Berlin to demonstrate its efficacy. Eichengrun also coined the name of the new drug in January 1899. Since salicylic acid could be obtained from the meadowsweet plant, an abbreviation of the plant's Latin genus-Spiraea-was put at the heart of the new brand name. "A" was added at the beginning to acknowledge acetylation, whereas "in" was tacked on to the end for easier pronunciation. However, Eichengrun was excluded from the official version of Bayer's history since 1934 because of his Jewish origin. Instead, it was claimed that aspirin was "discovered" by an "Aryan" scientist, Felix Hoffman, to alleviate the sufferings of his rheumatic father. Surprisingly, Bayer AG is still perpetuating this myth (www.bayeraspirin.com/questions/hundred_ aspirin.htm).

The second part of the book covers the story of the wonder drug from 1899 to 1945 . Aspirin played a key role in the $1918 \mathrm{flu}$ pandemic. It might also have had a crucial part in the collapse of the Russian empire. It is thought that Prince Alexei (the son of the last Russian emperor), who had haemophilia, was prescribed aspirin to reduce pain in his joints. This increased his bleeding. The illiterate quack Grigory Rasputin convinced the empress, Alexandra, to abandon modern treatments. Without aspirin the prince's health improved. The subsequent growth of Rasputin's power over the royal family "had been a significant factor in turning Russians against the Czar and in favour of revolution," says Jeffreys.

In the story of aspirin, politics and medicine are heavily intertwined. A chapter entitled "A moral collapse" provides documented stories of Bayer AG sponsoring Dr Mengele's experiments at Auschwitz. Information obtained from human guinea pigs was used for making and marketing commercial drugs. In 1956 the scientist Fritz ter Meer became a chairman of Bayer, after having been sentenced at the Nuremberg trials to seven years' imprisonment for his part in carrying out experiments on human subjects at Auschwitz. Auschwitz survivor Eva Mozes Kor, whom Jeffreys interviewed for his book, says that she has always tried to avoid taking any Bayer drugs, including Bayer aspirin.

The third part of the book tells the story of "aspirin's renaissance" in the second half of the 20th century. Prostaglandins were found to be responsible for pain and blood clotting. In June 1971 Nature published a seminal paper by John Vane and Priscilla Piper, "Inhibition of prostaglandin synthesis as a mechanism of action for aspirin-like drugs." The antiplatelet activity of aspirin has resulted in a new use for an old drug. After several clinical trials aspirin began to be marketed as a preventive treatment for secondary heart attacks. The next step was to use it for prevention of primary heart attacks and stroke. Recent studies demonstrate aspirin's potentially preventive effect on different types of cancer.

The aspirin companies quickly grasped the commercial possibilities of these new uses. The author notes that had it not been for those who ruthlessly exploited the commercial value of aspirin the drug might not have survived long enough to reveal its remarkable therapeutic secrets.

Boleslav L Lichterman Centre for the History of Medicine, Russian Academy of Medical Sciences, Moscow, Russia

licht@aha.ru

Items reviewed are rated on a 4 star scale (4=excellent) 
Aill

\section{Life Interrupted}

An exhibition of photographs by Don McCullin about HIV and AIDS, County Hall Gallery, London, until 10 January 2005 (open Friday to Sunday only), admission free

The exhibition will tour the UK and Ireland throughout 2005. See www.christian-aid.org.uk for further details

\section{Rating: $\star \star \star \star$}

W

ords and figures are not enough to describe the suffering that is caused by the AIDS pandemic. In his new exhibition, Life Interrupted, Don McCullin uses black and white photography to tell us the astounding stories of the people he has visited.

A world renowned photojournalist, McCullin travelled to South Africa and Zambia in 2000 to document the lives of people living with HIV. Earlier this year, he returned to the same countries with Christian Aid, a UK and Irish development agency.

When trying to track down families he had met on his previous journey to Zambia, McCullin was devastated by his findings: most of the people he had seen last time had died.

Teresa was one of these. She died only three months after McCullin had taken her photograph, leaving two children, Aaron and Mavis. When McCullin met Aaron, now 14, he gave him his mother's photograph. At first, Aaron turned away, his face in his

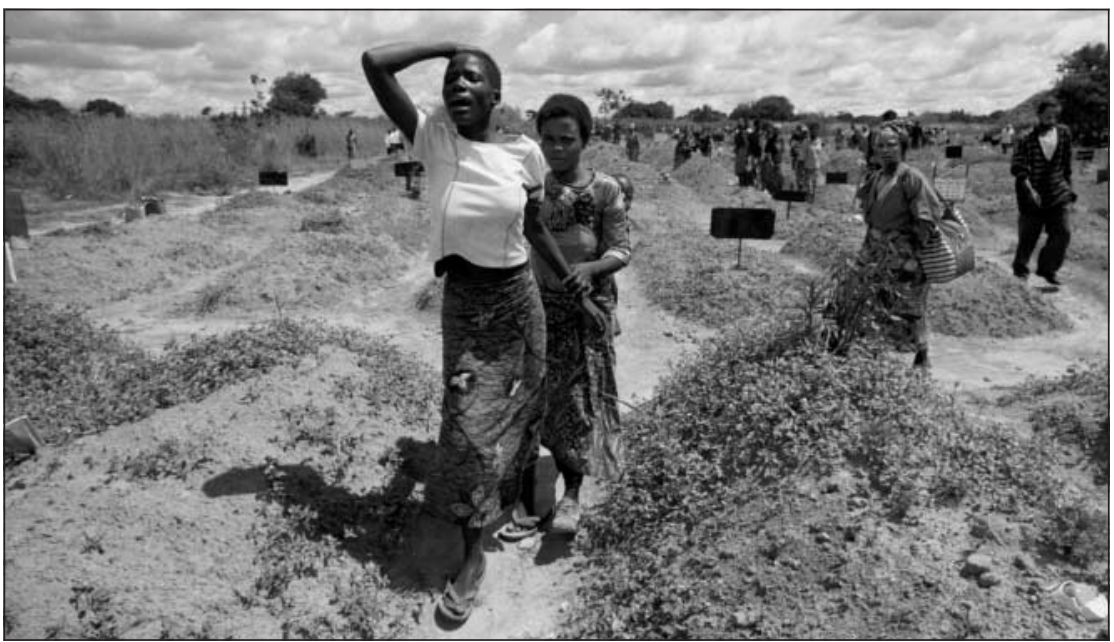

Kawama cemetery, Zambia: "The gravediggers have the most secure job"

hands. But after his initial shock, his face became wreathed in smiles as he hugged the photo to his chest, McCullin recalls.

McCullin also visited a cemetery in Zambia. "Four years ago, there was a steady tempo of burials. Now there seems to be a crescendo," he says. Andrew Banda, a local software engineer, adds: "The gravediggers have the most secure job in Zambia. It is a big, big business here."

Unlike Zambia, where HIV-positive people have to pay $£ 6(€ 8.67 ; \$ 11.65)$ a month to receive antiretroviral treatment, South Africa, which still has the highest number of HIV-positive people in the world, now offers treatment free of charge.

Although only a small minority of people who would need treatment receive it, examples show how big a difference it makes. Nomalunga remembers the day Don McCullin photographed her four years ago:
"I was so sick then, I thought I would die." Having received antiretroviral therapy, she feels much healthier today. She now looks after other patients, including Andiswa, who says: "It is important to me that she is also HIV-positive. She understands me. I remember when she was as sick as I am now."

The power of Life Interrupted is that McCullin's photographs show us how humans affected by HIV live-how they cry and how they laugh, how they die and how they find new life. They show us that we are all humans and that we are all affected, whether infected or not. Christian Aid comments: "His [McCullin's] photographs do more than bear witness. They compel us to act."

Raghav Chawla fifth year medical studen University of Lausanne, and BMJ Clegg scholar rchawla@bmj.com

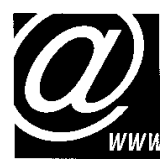

\section{Website aims to distance doctors from drug firms}

I $\mathrm{f}$ there is one thing for which 2004 will be remembered, it will surely be for exposing the cosy dynamics that have existed between the pharmaceutical industry, drug regulatory authorities, and the medical profession. But if the latest exploits of the US Food and Drug Administration (BMJ 2004;329:1253) and drug giants GlaxoSmithKline and Merck have left a nasty taste in your mouth, absolution is just a short URL away at the new UK website of the campaigning group No Free Lunch (www.nofreelunch-uk.org).
Launched last week, the site is cleverly constructed and encourages an open debate about the relationship between the drug industry and the medical profession without being anti-industry or taking itself too seriously.

A good starting point is the wonderful multiple-choice quiz "Am I a Pharma junkie?" It is easy to spot the answers that will score maximum points. But even if you do, the analysis of your score will raise a laugh or two and you will want to go through the quiz again and again until you have read all the possible characterisations.

But the best feature must be the offer of catharsis through the site's "confession" section, especially for those with uncomfortable memories of corporate hospitality and prescribing habits. A short description of your experience (no more than 200 words and anonymous, of course), a click on your return key, and you too can "become a born again ex-pharma junkie," the site promises.

There are already some confessions from doctors and journalists on the site, although pharmaceutical industry employees and nurses are also invited to contribute. Once absolved of your over-indulgence or guilt you can go straight to the "Take the pledge" section, where you can sign up for a gift-free, hospitality-free, and sponsorshipfree future and display your certificate for your colleagues to admire.

The site also has a newsroom (currently displaying news items from the $B M J$ but due to expand in the future), and useful pages of background information on how the pharmaceutical industry penetrates society.

Glasgow general practitioner Dr Des Spence, who set up the site with money earned writing articles about the Nofreelunch campaign, hopes it will help to distance doctors from the pharmaceutical industry. It will certainly bring a smile to many faces and maybe even a few puzzled brows among those who can't work out which pharmaceutical company logo is mimicked by the NFL bubble.

Zosia Kmietowicz freelance journalist, London zosia@blueyonder.co.uk 


\section{Bhopal: the lingering tragedy}

$\mathrm{I}$

$t$ was a bolt from the blue. In the early hours of the morning of 3 December 1984 toxic methyl isocyanate gas leaked out of the storage tanks of Union Carbide's plant in Bhopal, Madhya Pradesh, India. Residents awoke to clouds of suffocating gas and began a desperate flight through the dark streets. No warning alarm was given, and no evacuation plan had been prepared. It was an industrial disaster without parallel in history. Victims arrived at hospitals blind and with breathing problems. Doctors did their best to manage them, but it was an exercise in futility. The causative agent had not been identified, and so treatment was empirical. Only the next morning was the magnitude of the devastation seen. Dead bodies of humans and animals blocked the streets. Leaves had turned black, and an acrid smell lingered in the air. The sheer enormity of loss was heartbreaking. Destruction, under the guise of development, had smoked life out of the town.

Twenty years down the line the nightmare continues. A 40 year old woman breathes with difficulty in her one room home. Her husband works at a construction site. He is breathless even at rest. Prospective employers hesitate to take him on, because they view him as a liability. Both of them have interstitial lung disease resulting from exposure to methyl isocyanate gas. Treatment is free, but the prognosis is poor. With no steady source of income the couple's future looks bleak.

The Union Carbide plant had been a symbol of development in the town. It offered employment to many people, directly and indirectly. It was seen by the local population as a landmark to be proud of, and their hopes and aspirations were inextricably tied to it. It offered attractive salaries and was seen by many as a means to escape an impoverished existence. In hind-

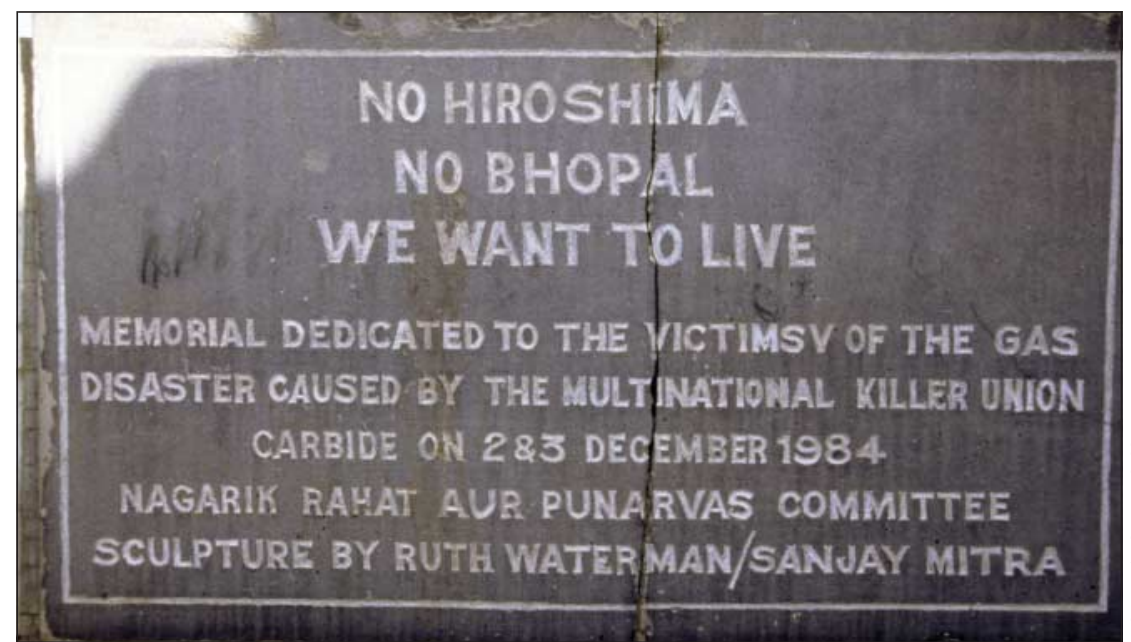

People who breathed in the gas are still dying today, 20 years after the disaster sight, however, there were only questionable benefits and unquestionably cruel costs.

Another tragic case: nearly two decades after he was exposed to the gas an expert in forensic medicine is admitted to a coronary care unit with severe cor pulmonale secondary to interstitial lung disease. With a courage born of firm conviction he had stayed in town right through the disaster and during its aftermath. His skills were needed in identifying bodies and understanding the organ pathologies caused by the toxic gas. His carefully documented autopsy findings formed the basis of our understanding of the gas's toxic effects. Extensive lung damage resulting from inhalation of the deadly vapours were the wages of his diligence. An unsung hero, he finally succumbed to the after effects of inhalation of the gas.

A nurse in an intensive care unit suddenly stops giving cardiopulmonary resuscitation to a patient, as she is mildly breathless and unable to go on. When questioned, she says that she has interstitial lung disease resulting from exposure to gas during the disaster. She is worried that she herself might need cardiopulmonary resuscitation soon. During the disaster she could not flee the town because she was on duty. Victims were crowding into her hospital. The result was that she became a victim herself. Consequent lung damage was the outcome of her dedication. Fiercely courageous, she starts the resuscitation again.

In the aftermath of the tragedy the victims were compensated for their losses. More financial compensation is in the offing. Free treatment and counselling for illnesses related and unrelated to exposure to the gas have been (and continue to be) provided Dependants of victims have been (and still are) given free medical care. Technically, the law has been followed. However, what goes unseen is the fact that the victims live with

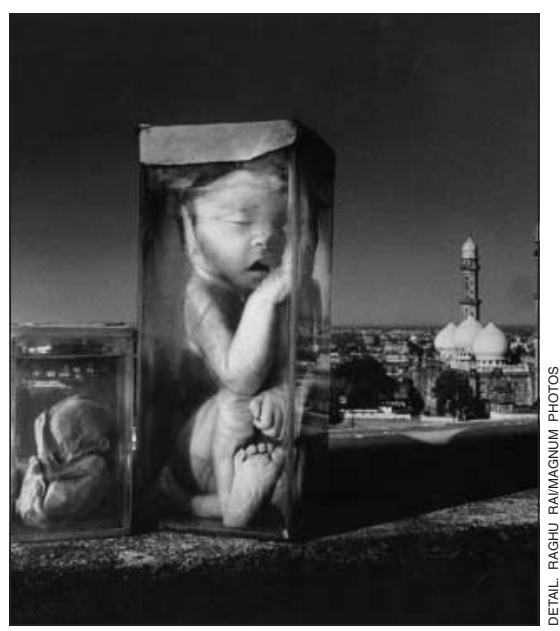

Fetuses aborted by pregnant women escaping the gas were preserved to establish the exact cause of death

the frustration of being chronically ill, anxiety about an inadequate income, and fear of becoming unwanted inconveniences in society. There is sense of a community brimming over with disappointments, frustrations, and aggravations. How long will it simmer before things come to a boil?

In the wake of such a disaster most settlements are made through courts of law. Usually financial compensation, free health care, and rehabilitation in terms of a job and a place to stay are offered. Long term social problems-probably as painful as the initial trauma-are often overlooked. Over time they fester and create myriad predicaments of their own. Frustrations and inadequacies begin to permeate every aspect of the survivors' lives. The consequences then have an effect on the community as a whole.

Perhaps it is time to review the entire procedure of settlements, compensation, and rehabilitation after any disasterindustrial or otherwise. Legal and financial issues are certainly important, but it is myopic to stop at just these. The long term psychosocial fallout of large scale disasters needs to be dealt with, in addition to the overt medical problems. Many of these needs may be unforeseen. The capacity to deal with these tribulations is an indicator of the resilience and health of a community; it is also an indicator of good governance. With a little insight it should be possible to incorporate sensitivity, perceptiveness, and flexibility into rehabilitation programmes. It would make victims' lives easier and the world a better place for them to adapt to. Would that be asking for too much?

Prabha Desikan associate professor, Bhopal Memorial Hospital and Research Centre, Bhopal, India prabhadesikan@yahoo.com 


\section{Pitfalls on the road to drug safety}

$\mathrm{T}$ he recent withdrawal of rofecoxib (Vioxx) from the worldwide market has focused intense public scrutiny on drug safety. Although the US Food and Drug Administration monitors drug safety after product approval, some have raised concerns about whether this system, which relies primarily upon voluntary reporting of adverse drug effects, is adequate to protect the public from unsafe pharmaceuticals.

In his televised appearance before the US Senate finance committee on 18 November, Dr David Graham, associate director in the FDA's Office of Drug Safety, claimed his own agency was "incapable of protecting [the public]" from other dangerous pharmaceuticals (BMJ 2004;329:1253). He then listed five drugs that he considered potentially unsafe- the acne drug isotretinoin (Roaccutane), the weight loss drug sibutramine (sold as Reductil in Britain and Meridia in the United States), the cyclooxygenase- 2 inhibitor valdecoxib (Bextra), the lipid lowering drug rosuvastatin (Crestor), and the asthma drug salmeterol (Serevent).

As a pulmonologist, I can only comment on the one drug on Dr Graham's list that I use frequentlysalmeterol. I have kept abreast of the literature on this agent and am aware of two potential problems with it: the use of salmeterol as opposed to a rapid onset bronchodilator (such as salbutamol, or albuterol, as it is known in the United States) to treat acutely deteriorating asthma; and the increased death rate observed in the SMART (salmeterol multi-center asthma research trial) and SNS (salmeterol nationwide surveillance (BMJ 1993;306:1034-7)) studies, in which salmeterol was given for maintenance without an accompanying inhaled steroid (such as fluticasone-the accompanying ingredient in Advair). In both of these instances, an excess of deaths has been reported, although the absolute increase in risk was rather small. Both of these precautions are listed in a "black box" on the package insert and should be well known to doctors using this drug.

The total number of patients currently taking salmeterol worldwide is more than 24 million, and my own experience as well as that of my many colleagues who treat asthma has been overwhelmingly positive with this agent. Shortly after the news of Dr Graham's "list" was broadcast, I started receiving calls from asthmatic patients who stopped taking this drug in response to the television reports and, predictably, noted their asthmatic symptoms increasing. A similar phenomenon occurred about eight years ago when news reports highlighted risks associated with calcium channel televised hearings. blockers in the treatment of coronary artery disease. Predictably, many patients stopped their calcium blockers, resulting in a number of acute coronary and cerebrovascular events that would not otherwise have occurred because of rises in (previously well controlled) blood pressure.

I am all for drug safety, but I am also for patient safety. Media treatment of these types of stories tends to glorify the whistleblower as a crusader for public safety, and usually ignores the fine print of what is well known by professionals in the relevant field. Many members of the lay public respond by acting impulsively-stopping their drugs-rather than discussing their individual circumstances with their doctors to see whether the alleged risks outweigh potential benefits in their particular case.

I am no fan of the big drug companies and have always opposed direct to consumer advertising of prescription drugs and direct to physician drug marketing. Both of these activities are aimed at marketing, rather than education. Overall the drug companies spend more on marketing annually than they do on research and development, and that is outrageous in my

opinion. The $15 \%$ annual rate of increase in drug costs (including yearly price increases for well established prescription drugs, not just new "miracle" drugs), which makes pharmaceuticals the single most profitable sector in the US economy, is a major driver of higher health costs and higher health insurance premiums. This needs to be changed if we are to bring health costs into a more reasonable range.

But at the same time, we need to be cautious about taking at face value the statements made by Dr Graham and others who appear to be champions of the vulnerable patient. In their efforts to promote patient safety, they may sometimes be causing more harm than good, and there may be better ways to achieve the goals of patient safety than making what I consider irresponsible statements on nationally

Carl Schoenberger pulmonologist, Bethesda, Maryland

mcschoenberger@aol.com

We welcome submissions for the personal view section. These should be no more than 850 words and should be sent electronically via our website. For information on how to submit a personal view online, see http://bmi.com/cgi/content/full/325/ 7360/DC1/1
SOUNDINGS

\section{Why doctors don't read research papers}

I have always rather liked mathematics. Patterns that are in no way discernible by intuition fall out with burning clarity when put under the lens of its methods. However, despite my awe, I find certain areas difficult. In particular I'm suspicious of algebra with its sleight of hand transformations of one thing into another. I see it this evening while watching my daughter doing her school prep. She obtains a simple formula, cranks the mechanical handle of algebraic manipulation, and out drops something else at the end. It is easy to lose sight of what is actually going on. The clarity is lost in the complexity of the method.

I find the same when trying to read medical papers. Sometimes it is the austere formulaic style of the prose that seems a bit dishonest. The authors affect the scientific style of the disinterested observer when in truth they are advocates of their idea. I find myself wanting to say: "Hey! If you want to persuade me to your view that this is important-be honest about it. Tell me what you think and then, honestly, why you think it."

The volume of statistical argument also seems part of the same disingenuous process. How many doctors have a clue what it means? Of all the areas of mathematics, probability, and its inscrutable daughter statistics, are the most slippery to grasp. Yet authors routinely drop large chunks of this extremely difficult stuff into papers that are supposed to be there to illuminate practice for doctors. But most doctors, including myself, don't understand it. It comes across as a sort of dishonest sleight of hand that is also a little patronising. It may be obvious to the professor and his acolytes but to mere mortals (who after all are the ones who actually see the patients) it merely seems like obscuring jargon.

I think that before any author drops any complex inferential statistics into a paper they should be obliged to give a commonsense interpretation of the data first: "Eyeballing this data seems to show that as X increases so does Y. The statistics suggest this is unlikely to be a chance event that arose because we only sampled a part of the population. And you aren't thick if you don't understand that bit because, truthfully, I don't either.' There. That wasn't so hard.

Kevin Barraclough general practitioner, Painswick, Gloucestershire 